\title{
¿Es el terrorismo de palabra un límite excesivo y desproporcionado al derecho fundamental a la libertad de expresión? El caso español
}

\author{
Is Spoken Terrorism Excessive and a Disproportionate Limit to \\ Fundamental Right of Freedom of Speech? The Spanish Case
}

Isabel SERRANO MAILLO ${ }^{1}$

\begin{abstract}
Resumen: En los últimos años en España están proliferando lo que se han venido a llamar leyes mordaza. Se trata de normas que limitan de manera exagerada y desproporcionada el derecho fundamental a la libertad de expresión. En este trabajo se pretende analizar si la inclusión en nuestro código penal (CP) de los delitos de enaltecimiento y justificación del terrorismo, así como el de humillación a las víctimas responden a esta tendencia o si, por el contrario, la limitación del derecho a la libertad de expresión en su nombre es legítima. El debate surge porque la inclusión de estos delitos ha supuesto la condena de miembros de la sociedad civil (raperos, blogueros, usuarios de Twitter) ajenos a la acción violenta, por comentarios jocosos que hasta ahora eran simples chistes o por opiniones que, si bien pueden ser rechazables y contrarias al sentir mayoritario, igualmente deben ser protegidas por la libertad de expresión. Y esto es así, porque en caso contrario, se produciría un desaliento que nos llevaría a la autocensura de aquellas opiniones que se encuentran en el margen de la legalidad resultando perjudicial para el debate público y la creación de una opinión pública libre.
\end{abstract}

Palabras clave: Libertad de expresión, terrorismo de palabra, principio de proporcionalidad, teoría del desaliento

\begin{abstract}
In recent years in Spain the "gag laws" is proliferating. These are rules that exaggeratedly and disproportionately limit the fundamental right to freedom of expression. This paper aims to analyze whether the inclusion in our criminal code of the crimes of exaltation and justification of terrorism, as well as that of humiliation to the victims respond to this trend or if,

1 Profesora Titular de Derecho Constitucional en la Facultad de Ciencias de la Información de la Universidad Complutense de Madrid. IP del Grupo de Investigación Regulación Jurídica y Participación del Ciudadano Digital. Licenciada en Derecho, Periodismo y Criminología. Doctora en Periodismo. Este trabajo se enmarca en los estudios del Programa de Doctorado en Derecho y Ciencias Sociales de la Universidad Nacional de Educación a Distancia. miserran@ucm.es
\end{abstract}


on the contrary, the limitation of the right to freedom of expression on their behalf is legitimate. The debate arises because the inclusion of these crimes has led to the condemnation of members of civil society (rappers, bloggers, Twitter users) oblivious to the violent action, for humorous comments that until now were simple jokes or for opinions that, although they can be objectionable and contrary to the majority sentiment, they must also be protected by freedom of expression. And this is so, because otherwise, there would be a discouragement that would lead us to self-censorship of those opinions that are on the margin of legality, resulting detrimental to public debate and the creation of a free public opinion.

Keywords: Freedom of Speech, Spoken Terrorism, Principle of Proportionality, Discouragement Theory

\section{Introducción}

La libertad de expresión se configura en España como un derecho fundamental cuyo fin último es la creación de una opinión pública libre, base de nuestra democracia. No se trata de un derecho absoluto, pero sí de un derecho preferente dada la relevancia del fin que persigue. A pesar de ello, en los últimos años se están aprobando en nuestro país normas que, aparándose en bienes jurídicos como la seguridad, limitan la libertad de expresión de manera injusta y desproporcionada. Un claro ejemplo es nuestro código penal, al que se han ido añadiendo como delitos conductas que, si bien son reprochables, deberían estar protegidas bajo el amparo de la libertad de expresión — ciertos tipos de discurso del odio o las injurias al rey-. En este trabajo nos proponemos estudiar si la incorporación a nuestro código penal de los delitos de enaltecimiento y justificación del terrorismo, así como el de humillación a las víctimas responde a este patrón de las leyes mordaza o si, por el contrario, son conductas que deben ser castigadas.

El objetivo es analizar cómo estas acciones tipificadas como terrorismo en la legislación española pueden suponer un límite excesivo, injusto y desproporcionado a la libertad de expresión. Son comportamientos que consisten en ensalzar o justificar la violencia terrorista (terrorismo de palabra), pero que son realizados por personas ajenas al entorno terrorista cuyas palabras, supuestamente, no pretenden provocar violencia. Se explicará lo que se entiende por terrorismo de palabra, se analizará brevemente la legislación española sobre libertad de expresión y cómo deben resolverse los conflictos en este ámbito y, finalmente, se expondrán diversos casos judiciales en los que se condenó a miembros de la sociedad civil por terrorismo (por bromas, mensajes en Twitter, blogs, etc.), si bien algunos de ellos fueron absueltos posteriormente por el Tribunal Supremo o el Constitucional, por entender que se había vulnerado su libertad de expresión. 


\section{Breves apuntes previos sobre el terrorismo en España su regulación}

Antes de entrar a valorar si está justificada o no la tipificación de estos delitos, a los que llamaremos "terrorismo de palabra" 2 y, por tanto, el sacrificio de la libertad de expresión —en aras de una sociedad más segura - es necesario que hagamos un rápido repaso por la historia del terrorismo en España y los años de terror vividos en nuestro país. Para entender el porqué de las leyes de un lugar determinado es preciso conocer su historia, dado que muchas son reflejo de las experiencias vividas como sociedad y como nación. El grupo terrorista más significativo en nuestro país ha sido $\mathrm{ETA}^{3}$, grupo especialmente violento que entre sus comienzos (1968) y el cese definitivo de su actividad armada (2011) cometió 2.472 atentados terroristas, acabó con la vida de 829 personas (militares, políticos, civiles y niños) y dejó 2.597 heridos. Junto a esta organización actuaron otras de menor relevancia como GRAPO ${ }^{4}$ (84 asesinados) o TERRA IURE 5 (200 atentados, con 5 víctimas) entre otras. Actualmente, la amenaza se centra en los grupos yihadistas, que en España ya se han cobrado 209 víctimas mortales y más de 2.000 heridos en tan solo dos atentados: uno en Madrid el 11 de marzo de 2004 (hicieron explosionar cuatro trenes de cercanías en los que murieron 193 personas) y otro en Barcelona el 17 de agosto de 2017, reivindicado por el grupo "DAESH"6. Es importante partir de esta realidad política para comprender cómo se integra en nuestra legislación el fenómeno terrorista. Entendemos que

el terrorismo no es un fenómeno coyuntural sino estructural, razón por la cual la lucha contra el mismo ni puede ser de tipo militar (caso de EEUU), ni puede realizarse mediante la adopción de normas excepcionales y extraordinarias (caso del Reino Unido), sino a través de la legislación ordinaria, de conformidad con los principios inherentes a un Estado de Derecho ${ }^{7}$.

En España no existe una ley especial antiterrorista, sino que este tipo de delitos se recoge en el Código Penal. Estos se incorporaron definitivamente a dicho código en 1995, que fue objeto

\footnotetext{
${ }^{2}$ Serrano (2020).

3 ETA: Este grupo terrorista tenía como principal objetivo la construcción de un estado socialista en el País Vasco y su independencia de España y Francia. Durante sus primeros años contó con el apoyo de la población vasca porque fue una de las muchas organizaciones que se opusieron a la dictadura franquista. Una vez aprobada la Constitución, perdió su sentido y gran parte del apoyo popular vasco, aunque siempre contó con el apoyo político del partido político Herri Batasuna, encabezado por Otegui. ${ }^{4}$ GRAPO: Grupo de Resistencia Antifascista Primero de Octubre. Es una organización terrorista española nacida en Galicia en 1975 con el objetivo de establecer una "república popular y federativa" en España (Jiménez. 2012. P. 113) Es considerado grupo terrorista por la Unión Europea (Gaceta Oficial № L 099 del 03/04/2004 p. 0061 - 0064) y por el Departamento de Estado de los Estados Unidos (Informes nacionales sobre terrorismo 2004).

${ }^{5}$ TERRA IURE (tierra libre): Fue una organización terrorista española fundada en 1978 y disuelta en 1991. Su objetivo era construir una Cataluña socialista independiente de España. Algunos de sus dirigentes y militantes se unieron posteriormente a la Esquer ra Republicana de Catalunya (ERC), que les exigía que renunciaran explícitamente al terrorismo como condición para ingresar. [https://bit.ly/3laudNX].

${ }^{6}$ DAESH: Grupo terrorista también conocido como Estado Islámico. Es un grupo terrorista fundamentalista yihadista. Es conocido por sus cruentos atentados, decapitaciones, asesinatos, destrucción de patrimonio histórico... Ha sido catalogado como organización terrorista por la Organización de las Naciones Unidas.

${ }^{7}$ Álvarez y González (2006), p. 2.
} 
de una importante modificación en 2000 (cuando se incorporó el polémico artículo 578 (sobre el enaltecimiento y justificación pública del terrorismo) y de otra en 2015 (momento en que se reordenaron todas estas acciones bajo la rúbrica: “De las organizaciones y grupos terroristas y de los delitos de terrorismo") que introdujo cambios importantes orientados al agravamiento de las penas por actos terroristas, por un lado, y a la expansión de actitudes y acciones que pueden considerarse terrorismo, por otro.

En España (aunque lo habitual es que las normas antiterroristas aparezcan recogidas en el Código Penal, como decimos) podemos encontrar algunas otras leyes que también incluyen consecuencias jurídicas para aquellos que de una manera no violenta den cobertura al terrorismo. Así, la Ley Orgánica 6/2002, por ejemplo, considera causa de ilegalización de un partido político, el "dar apoyo político expreso o tácito al terrorismo, legitimando las acciones terroristas para la consecución de fines políticos a margen de los cauces pacíficos y democráticos, o exculpando y minimizando su significado y la violación de derechos fundamentales que comporta" (art. 9.3 a).

Este artículo ha dado lugar a diversas sentencias judiciales sobre cuestiones de gran relevancia para el Derecho Constitucional, en concreto, si el hecho de no condenar los atentados terroristas implicaba necesariamente un apoyo tácito al mismo y, por tanto, motivo de ilegalización o si por el contrario esta exigencia supondría un límite exagerado a la libertad de expresión ${ }^{8}$. Lo tribunales españoles se mostraron unánimes a este respecto, considerando que la libertad de expresión incluía tanto el derecho a opinar como el derecho a no hacerlo. El silencio por sí mimo, pues, no puede ser considerado prueba irrefutable de apoyo al terrorismo si no va acompañado de otros actos. No obstante, el Tribunal Supremo apostilló que cuando se trata de formaciones políticas, "hay que aceptar como razonable, proporcional y adecuada la exigencia de que las organizaciones y agrupaciones que pretenden participar en las instituciones públicas realicen un rechazo inequívoco y concreto al terror" 9 .

Así pues, cuando hablamos de terrorismo también podemos encontrarnos en el ámbito de la palabra, de conductas que inducen a que otros cometan estos actos o que ensalzan a aquellos que los cometieron o que humillan a los que vieron morir a los suyos o a los que fueron víctimas directas del terror. Esto es así porque nuestra democracia entiende que, aunque son actos que

${ }^{8}$ Tribunal Supremo, STS 2133/2003, de 27 de marzo de 2003.

${ }_{9}^{9}$ Tribunal Supremo, STS 2133/2003, de 27 de marzo de 2003 y Tribunal Constitucional, STC 5/2004, de 16 de e nero de 2004 y STC 99/2004, de 27 de mayo de 2004. 
no matan físicamente, son acciones que agreden psicológicamente y ofenden a los valores democráticos y constitucionales que imperan en una sociedad democrática ${ }^{10}$.

Es fácilmente comprensible que este tipo de discurso sea sancionado como terrorismo a pesar de no matar, pero en ocasiones resulta difícil discernir si alguna de estas acciones no es más que la expresión de una opinión (pensemos en las manifestaciones hechas por sujetos ajenos al entorno terrorista). Son opiniones reprobables y despreciables, podrían estar protegidas bajo el paraguas de la libertad de expresión.

\section{Terrorismo de palabra}

El término "terrorismo de palabra" se refiere a todos aquellos delitos que nuestra legislación tipifica como delitos de terrorismo, pero que no consisten en ataques físicos, sino en acciones que alientan, justifican o aplauden a los terroristas y sus actos. Delitos que, como veremos, pueden entrar en conflicto con la libertad de expresión.

Se trata de analizar solo aquellos actos que consisten en hacer algún tipo de manifestación o expresión de opiniones y se tipifican como delitos de terrorismo. En España, básicamente son: la apología (art. 18.1 CP), el enaltecimiento o la justificación del terrorismo y la humillación a las víctimas del terrorismo o a sus familias (art. $578 \mathrm{CP}$ ).

Apología, enaltecimiento y justificación son conceptos muy parecidos, como podemos observar al comparar sus definiciones dadas por el Diccionario de la Real Academia Española de la Lengua (RAE). La apología sería un "discurso de palabra o por escrito, en defensa o alabanza de alguien o algo"; el enaltecimiento sería la "acción de enaltecer", enaltecer, a su vez, significa ensalzar, cuyo significado es engrandecer: aumentar, hacer grande algo, alabar, exagerar, exaltar, elevar a alguien a grado o dignidad superior; la justificación es la "acción y efecto de justificar", que a su vez significa "probar algo con razones convincentes". En el ámbito jurídico, por su parte, cada una de estas acciones tiene su especificidad, aunque puede ser difícil diferenciar unas conductas de otra, pues todas ellas tienen como base la expresión de una idea, aunque difieren en el objetivo que persiguen. La doctrina considera que todas ellas son una forma de apología -

${ }^{10}$ Fernández (2010), p. 44; Ruiz (2002), p. 82. 
especialmente la primera-, es decir, de provocación a la comisión de actos terroristas, aunque a cada una se le atribuyen unos aspectos específicos ${ }^{11}$.

La apología, (artículo 18.1 CP) se entiende como

la exposición, ante una concurrencia de personas o por cualquier medio de difusión, de medidas o doctrinas que ensalcen el crimen o enaltezcan a sus autores. La apología sólo será delictiva como forma de provocación y si por su naturaleza y circunstancias constituye una incitación directa a cometer un delito;

el enaltecimiento consiste en alabar y justificar la conducta y delitos cometidos por los terroristas, dando apariencia de lícito a comportamientos prohibidos por la ley y la justificación del terrorismo consiste en aprobar la conducta de los terroristas, considerando que habría razones para comportarse del modo que lo hicieron. En el enaltecimiento y en la justificación no se trataría de provocar violencia directamente, sino de reforzar y apoyar "actuaciones criminales muy graves y la sostenibilidad y perdurabilidad de las mismas".

Todas estas conductas tienen elementos esenciales en común: todas están orientadas a mostrar aprobación por las conductas terroristas (en diferente grado), para ser punibles tienen que realizarse personalmente ante un público que escucha las manifestaciones del actor o a través de un medio de difusión (cualquiera) y que inciten de alguna forma a la violencia de manera directa como en la apología, o de forma indirecta, como en el resto de los casos. Este matiz, aunque pudiera parecer lo contrario, no siempre resulta suficiente para determinar ante qué delito nos encontramos. De hecho, es habitual que los tribunales condenen bajo la fórmula genérica de "enaltecimiento y justificación" del terrorismo, bien porque concurren ambas conductas o bien porque no es fácil distinguirlas.

El delito de humillación a las víctimas del terrorismo o sus familias tiene un contenido diferente, ya que se trata de realizar actos que entrañen descrédito, menosprecio o humillación de estas personas. Según el Diccionario de la RAE de la Lengua descrédito supone la "disminución o pérdida de reputación de las personas". Menosprecio supone "desprecio", "desestimación”. Humillación, "herir el amor propio o la dignidad de alguien”. Se trata de conductas que persiguen vilipendiar, mofarse o burlarse de quienes han sufrido las consecuencias de los actos terroristas o sus familiares. En este caso, para que la conducta sea punible no es necesario que se haga con publicidad $^{12}$. Esta conducta está directamente relacionada con el delito de injurias (art. $208 \mathrm{CP}$ :

\footnotetext{
${ }^{11}$ Arias (2007), p. 21.

12 Dolz (2013), p. 4.
} 
“Acción o expresión que lesiona la dignidad de otra persona, menoscabando su fama o atentando contra su propia estimación") o con ofensas menos graves al honor reguladas por la legislación civil, concretamente por la Ley Orgánica 1/1982.

El delito de apología ya figuraba en el Código Penal (1995), mientras que los de enaltecimiento, justificación y humillación a las víctimas entran en él con una modificación del año 2000. La reforma de este artículo se produce en un momento en el que los atentados terroristas de ETA eran frecuentes, con lo que se pretendía que tuviera efectos preventivos.

Esta ampliación de casos, unida a que el castigo es más severo si se difunden a través de los medios de comunicación o Internet ${ }^{13}$ (la forma más frecuente de cometer estos delitos en la actualidad), ha llevado a la condena de cantantes de rap (como a Hasel ${ }^{14}$ y Valtonyc ${ }^{15}$, por exaltar el terrorismo en sus canciones), blogueros y usuarios de Twitter (como a Fernando de Reyna ${ }^{16}$ por un delito de humillación a víctimas de terrorismo). Esta situación ha provocado un debate sobre si las reformas recientes están limitando la libertad de expresión de manera injusta y desproporcionada, dado que la acción a través de las redes es cada vez más común ${ }^{17}$. La polémica surge porque tras la inclusión de los nuevos delitos, se está condenando por terrorismo a algunos miembros de la sociedad civil, ajenos a la acción violenta ya a los movimientos terroristas. Bromas o comentarios jocosos que hasta hace poco eran simples chistes (o humor negro) u opiniones más o menos acertadas, ahora pueden ser castigadas. La falta de consenso entre el legislador y los tribunales y la disparidad de criterios encontrados en la jurisprudencia no ayuda a la situación actual. Esto tiene claras implicaciones para la libertad de expresión, que no es un derecho absoluto e ilimitado, pero debe recibir una protección especial o al menos efectiva, ya que su objetivo fundamental, como decíamos, es crear un espacio para la opinión pública libre donde fluyan todo tipo de opiniones, aunque algunas sean diferentes o contrarias a lo que piensa la mayoría.

\footnotetext{
${ }_{13}^{13}$ En la reforma del año 2015 se endurecieron las penas por estas conductas pudiendo llegar a los tres años de prisión (lo que podría suponer la entrada efectiva en la cárcel) "cuando los actos se realizaban mediante la difusión de servicios o contenid os accesibles al público a través de los medios de comunicación, Internet, o mediante servicios de comunicaciones elect rónicas o mediante el uso de tecnologías de la información" (art. 578.2 CP).

${ }_{14}$ Audiencia Nacional, SAN 8/2014, de 31 de marzo de 2014 y Tribunal Supremo, STS 748/2015, de 19 de febrero de 2015. Sentencia en la que se condena al cantante Hasel (por las letras de sus canciones) por enaltecimiento del terrorismo.

${ }_{15}$ Audiencia Nacional, SAN 494/2017, de 12 de febrero de 2017 y Tribunal Supremo, STS 397/2018, de 15 de febrero de 2018. Sentencia en la que se condena al cantante Valtonyc (por las letras de sus canciones) por enaltecimiento del terrorismo.

16 Audiencia Nacional, SAN 25/2017, de 11 de diciembre de 2017. Sentencia en la que se condena al Reyna, por un mensaje es Twitter, por enaltecimiento del terrorismo.

17 Tapia (2016), p. 3.
} 


\section{El derecho fundamental a la libertad de expresión en el Derecho español y europeo}

La libertad de expresión en España se configura como un derecho fundamental y consiste en el derecho a "expresar y difundir libremente los pensamientos ideas y opiniones mediante la palabra, el escrito o cualquier otro medio de reproducción" (art. 20.1 a) Constitución Española). No es un derecho absoluto ${ }^{18}$, pero es un derecho preferente, en el sentido de que solo está delimitado por el interés público y que no implique injuria. Esto implica que estarán protegidas aquellas opiniones sobre asuntos de interés que resulten relevantes para la formación de una opinión pública libre y no sean injuriosas. Por el contrario, carecerán de tal efecto legitimador "cuando (...) se ejercite de manera desmesurada y exorbitante del fin en atención al cual la Constitución le concede su protección preferente"19.

Hay que apuntar que, en nuestra legislación, la libertad de expresión ${ }^{20}$ (difundir ideas) es un derecho diferente del derecho a la información (emitir y recibir información veraz). La libertad de expresión es un derecho más amplio al no exigir que las opiniones sean veraces, lo que sí es necesario en las informaciones. El Convenio para la Protección de los Derechos Humanos y de las Libertades Fundamentales, por su parte, considera que la libertad de expresión se articula como un derecho único que integra la libertad de opinión, por un lado, y la de recibir o de comunicar informaciones, por otro (art.10). El TEDH ha destacado la necesidad de diferenciar entre hechos y opiniones, dado que el tratamiento no será igual si se trata de estas que si se trata de aquellos. Y esto, porque los hechos son susceptibles de prueba y se les puede exigir el requisito de veracidad, mientras que las opiniones no pueden ser comprobadas ni, por tanto, sometidas al control de la verdad. No obstante, es importante matizar que el bien jurídico protegido por la libertad de expresión "no sería la libertad personal de opinar, sino la libertad de comunicar juicios o ideas. Esta puntualización es importante, dado que comunicar conlleva una carga informativa superior" 21. Así, aunque no se les pueda exigir veracidad, "a las opiniones ha de exigírseles que se realicen con criterio o, al menos, con sinceridad". Asimismo, "incluso cuando una declaración equivale a un juicio de valor (...) debe tener suficiente base factual coincidencia con el referente externo-, sin lo cual sería excesiva”22.

\footnotetext{
${ }^{18}$ Mir y Corcoy (2012), p. 13.

${ }^{19}$ Tribunal Constitucional, STC 171/1990, de 12 de noviembre de 1990, Fundamento Jurídico 6.

${ }^{20}$ Sánchez de Diego (2010), p. 5.

${ }^{21}$ Galvez (1980), p. 401.

22 Tribunal Europeo de Derechos Humanos, STEDH de 27 de febrero de 2001, § 43.
} 
El mayor intérprete de este derecho en nuestro país es el Tribunal Constitucional. Sus primeras sentencias sobre libertad de expresión datan de 1980 y, desde entonces, ha ido modulando el significado de este derecho. En relación con la libertad de expresión y los delitos que estamos tratando ha dictado varias sentencias en la línea de considerar que la "libertad de expresión comprende la libertad de crítica aun cuando la misma sea desabrida y pueda molestar, inquietar o disgustar a quien se dirige, pues así lo requieren el pluralismo, la tolerancia y el espíritu de apertura, sin los cuales no existe sociedad democrática"23. Hemos de entender, por lo tanto, que "la libertad de expresión vale no solo para la difusión de ideas u opiniones acogidas con favor o consideradas inofensivas o indiferentes, sino también para aquellas que contrarían, chocan o inquietan al Estado o a una parte cualquiera de la población"24, y es que, como decía George Orwell en su Rebelión en la Granja, (1945) "Si la libertad significa algo, es el derecho de decirles a los demás lo que no quieren oír". ¿Pero dónde está el límite?

El Tribunal de Estrasburgo, a pesar de reconocer que la libertad de expresión no es un derecho absoluto, se ha mostrado muy estricto a la hora de permitir injerencias en el mismo por parte de los Estados. Así, ha establecido claramente las condiciones que deben cumplir las medidas nacionales impuestas en este sentido para ser compatibles con el Convenio 25 .

En primer lugar, se exige que la medida restrictiva esté prevista por la ley; en segundo lugar, que la limitación esté justificada por alguno de los fines establecidos en el apartado 2 del artículo 10 del Convenio y, por último, que la medida sea necesaria dentro de una sociedad democrática. Las dos primeras condiciones no presentan mayores complicaciones, ya que no conllevan ninguna operación que no sea más o menos automática. Así, en el primer caso el Tribunal solo debe contrastar la existencia efectiva de una ley nacional que recoja la limitación ${ }^{26}$ y, en el segundo, que la misma responda a la consecución de uno de los objetivos previstos en el art. 10.2 del Convenio. La última condición, hace referencia a dos aspectos esenciales: la necesidad de la injerencia en una sociedad democrática y la proporcionalidad entre la medida y el objetivo que se persigue conseguir. Esta última operación "es sin duda la más conflictiva y en ella se cifra la resolución de los conflictos planteados ante el Tribunal”27.

\footnotetext{
${ }^{23}$ Tribunal Constitucional, STC 174/2006, de 5 de junio de 2006 y STC 177/2015, de 22 de julio de 2015.

24 Tribunal Europeo de Derechos Humanos, STEDH de 24 de febrero de 1997, § 49.

${ }^{25}$ Korff (1998).

${ }^{26}$ Suárez (2007), p. 4

${ }^{27}$ Gay (1989), p. 268.
} 
La medida de necesidad de injerencia significa, según se desprende de la jurisprudencia del Tribunal Europeo de Derechos Humanos, que tal injerencia debe responder a una "necesidad social imperiosa"28, lo que no significa imprescindible, pero tampoco que se pueda justificar motivos de oportunidad o pertinencia, ni porque la misma resulte razonable. Es fundamental que las autoridades nacionales hagan una correcta valoración y ponderación de los intereses en conflicto (el derecho del individuo que se pretende restringir, por un lado, y el fin que persigue el Estado con esa restricción, por otro), para poder asegurar que se produzca un justo equilibrio entre todos los intereses implicados en el caso.

La exigencia de proporcionalidad, por su parte, implica la comprobación de que las ventajas que se obtienen con la injerencia en el derecho fundamental compensan los sacrificios que esta implica para sus titulares y para la sociedad en general. Si no es así, o existe un medio menos gravoso para el derecho fundamental en cuestión con el que se consiga el mismo fin, se entenderá que no se cumple el requisito de proporcionalidad. El principio de proporcionalidad vendría a ser una suerte de "límite de los límites a los derechos fundamentales"29.

Cabe hacer referencia aquí, a la doctrina del margen de apreciación ${ }^{30}$, que admite que los Estados gocen de cierta libertad a la hora de restringir algunos derechos fundamentales, si bien será el Tribunal Europeo de Derechos Humanos el que, en última instancia, ejercerá el control sobre dichas injerencias estatales para determinar si son admisibles o no. Esta licencia para los Estados nacionales se explica porque hay ciertas cuestiones tan vinculadas a la cultura y realidad de cada país que difícilmente podrían ser mejor interpretadas por un tribunal ajeno. Así, el margen de apreciación será mayor o menor dependiendo del grado de uniformidad existente sobre un concepto determinado en las legislaciones de los países firmantes del Convenio. Sobre aquellas cuestiones en las que haya menos consenso, por su condicionamiento por factores sociales o culturales, como decíamos, los Estados tendrán un mayor margen de apreciación, mientras que en los que exista gran uniformidad, el margen de apreciación será muy reducido o, incluso, inexistente. Así, por ejemplo, será muy amplio en casos relacionados con la moral y, muy limitados en asuntos concernientes a la imparcialidad judicial. Este margen de apreciación está especialmente restringido en los casos relativos a la libertad de expresión, lo que ha explicado reiteradamente el Tribunal Europeo de Derechos Humanos, basándose en que este derecho, es

\footnotetext{
${ }^{28}$ Tribunal Europeo de Derechos Humanos, STEDH de 25 de junio de 2002, § 57; STEDH de 7 de diciembre de1976; STEDH de 8 de julio de 1986, §39.

${ }^{29}$ Bernal (2007), p. 523.

${ }^{30}$ García (2010).
} 
uno de los pilares fundamentales de las sociedades democráticas. De ahí que no se pueda dejar al libre arbitrio de las autoridades nacionales el establecimiento de límites que puedan llegar a ahogar esa libertad.

El ordenamiento jurídico multinivel que actualmente está vigente en Europa, en el ámbito de los derechos fundamentales, ha producido modificaciones respecto del contenido protegible de los derechos fundamentales en los ordenamientos jurídicos nacionales, aunque siempre bajo la premisa de que no existen derechos fundamentales absolutos. Los derechos fundamentales no pueden, ni deben, ser ilimitados, sino que todos están sujetos a limitaciones ${ }^{31}$.

Entre los límites a la libertad de expresión se encuentran las conductas tipificadas por la ley penal, si bien es esencial delimitar sus contornos de manera exacta y restrictiva, para evitar que la libertad de expresión quede tan constreñida por la ley que pierda su razón de ser:

no se trata, con toda evidencia, de prohibir el elogio o la defensa de ideas o doctrinas, por más que éstas se alejen o incluso pongan en cuestión el marco constitucional, ni, menos aún, de prohibir la expresión de opiniones subjetivas sobre acontecimientos históricos o de actualidad. Por el contrario, se trata de algo tan sencillo como perseguir la exaltación de los medios terroristas, radicalmente ilegítimos desde cualquier perspectiva constitucional, o de los autores de estos delitos, así como las conductas especialmente perversas de quienes calumnian o humillan a las víctimas al tiempo que incrementan el horror en sus familiares ${ }^{32}$.

Entonces... ¿Qué hay que tener en cuenta para determinar qué debe y qué no debe ser condenado? Desde nuestro punto de vista, debe tenerse en cuenta no solo las palabras, sino también la intención de estas y el contexto en que se estén utilizando. Dicho esto, somos conscientes de que se trata de incluir conceptos sumamente subjetivos como el de la intencionalidad. Pero así lo ha entendido también nuestro Tribunal Constitucional, cuando dice:

En esta clase de delitos es importante, no solo el tenor literal de las palabras pronunciadas, sino también el sentido o la intención con que han sido utilizados, pues es evidente que el lenguaje admite ordinariamente interpretaciones diversas $y$, a los efectos de establecer la responsabilidad por un delito de enaltecimiento del terrorismo es preciso determinar con claridad en cuál de los posibles significados ha sido utilizado en cada ocasión concreta ${ }^{33}$.

\section{5. ¿Cuándo debe prevalecer la libertad de expresión sobre el "terrorismo de palabra"?}

Debemos partir de un principio esencial: Los Jueces no pueden hacer una interpretación extensiva de las normas penales que limiten la libertad de expresión de manera excesiva.

\footnotetext{
${ }^{31}$ Moreno (2017), p. 324.

32 Preámbulo de la Ley 7/2000, de 22 de diciembre, de modificación del Código Penal.

33 Tribunal Constitucional, STC 112/2016, de 22 de junio de 2016.
} 
El Juez (...) ha de tener siempre presente su contenido constitucional para no correr el riesgo de hacer del Derecho penal un factor de disuasión del ejercicio de la libertad de expresión, lo que, sin duda, resulta indeseable en un Estado de Derecho... Así las cosas, el órgano judicial debe valorar, como cuestión previa a la aplicación del tipo penal y atendiendo a las circunstancias concurrentes en el caso concreto, si la conducta que enjuicia constituye un ejercicio lícito del derecho fundamental de la libertad de expresión y, en consecuencia, se justifica por el valor predominante de la libertad de expresión ${ }^{34}$.

No hay duda respecto a que cuando existe un riesgo real de generar violencia (caso de la apología), el discurso debe ser prohibido y la conducta sancionada. Existe un amplio consenso en cuanto a que la libertad de expresión deber ser limitada cuando

conlleve el riesgo de que puedan cometerse actos terroristas. En cada caso concreto, al examinar si se ha materializado ese riesgo se deben tener en cuenta las circunstancias específicas de cada caso, como el autor y el destinatario del mensaje, así, como el contexto en el que se haya cometido el acto. También deben considerarse la importancia y la verosimilitud del riesgo al aplicar la disposición sobre provocación pública de acuerdo con el Derecho nacional (Directiva (UE) $2017 / 541)^{35}$.

Lo que implica valorar el contexto, el emisor, el receptor y la posibilidad de que se genere efectivamente violencia.

La duda surge en relación con aquellas conductas que, sin suponer un riesgo real de provocar violencia, se enmarcan en lo que venimos llamando "terrorismo de palabra", —el enaltecimiento y la justificación del terrorismo. Ante las dificultades de establecer el límite de hasta dónde amparada la libertad de expresión ciertas conductas que podrían ser constitutivas de delito, los tribunales han reiterado que se han de valorar cuidadosamente los hechos tanto para determinar si la conducta es delictiva como, en su caso, para fijar la pena que se contempla para ellos. Se han de ponderar y examinar minuciosamente todas las circunstancias objetivas y subjetivas que concurren para resolver si prevalece la libertad de expresión frente a la conducta que enaltece o justifica la violencia. En muchas de las resoluciones del Tribunal Supremo se insiste en esta cuestión, poniendo con ello de manifiesto las dificultades que existen para

\footnotetext{
34 Tribunal Constitucional, STC 177/2015, de 22 de julio de 2015, Fundamento Jurídico 2.

${ }^{35}$ La Directiva (UE) 2017/541, reconoce que “(2) Los actos terroristas constituyen una de las violaciones más graves de los valores universales de la dignidad humana, la libertad, la igualdad y la solidaridad, y el disfrute de los derechos humanos y de las libertades fundamentales, en los que se basa la Unión. También representan uno de los ataques más graves contra la democracia y el Estado de Derecho, principios que son comunes a los Estados miembros y en los que se fundamenta la Unión", lo que hace necesario (dice en el párrafo 6) que se establezcan definiciones comunes sobre qué debe entenderse por terrorismo, cuáles deben ser considerados como delitos anexos y, además, exige que los Estados se comprometan a hacer todo lo posible para controlar este fenómeno, incluido lo que tiene que ver con la difusión del mensaje terrorista (párrafos 11 a 39). Les insta para que adopten medidas que garanticen la tipificación como delito de aquellas conductas intencionadas que consistan en difundir mensajes destinados a incitar a la comisión de este tipo de delitos. La recomendación exige, no obstante, que esto se haga protegiendo y respetando las libertades de expresión e información: "Ninguna disposición de la presente Directiva podrá interpretarse como un intento de reducir u obstaculizar la difusión de información con fines científicos, académicos o informativos. La expresión pública de opiniones radicales, polémicas o controvertidas sobre cuestiones políticas delicadas queda fuera del ámbito de aplicación de la presente Directiva y, en especial, de la definición de provocación pública a la comisión de delitos de terrorismo" (párrafo 40).
} 
resolver los temas sobre los que se han de pronunciar: condenar por enaltecimiento o justificación del terrorismo o humillación a las víctimas o absolver por estimar que el sujeto ha actuado amparado por el derecho constitucional a la libertad de expresión. Así, como expone el Tribunal Constitucional, la ponderación va a ser un elemento esencial ${ }^{36}$.

Parece, pues, que la limitación de la libertad de expresión no puede considerarse como la norma general, sino que solo será legítima cuando tras el estudio del caso y realizada una correcta ponderación podamos concluir que las manifestaciones realizadas suponen un riesgo real de provocar violencia terrorista o un riesgo real para las personas o para el propio sistema de libertades. En el resto de los casos prevalecerá la libertad de expresión.

Así, solo la apología debería actuar como límite a la libertad de expresión, quedando inhabilitados para ello el enaltecimiento o la justificación si se hacen fuera de un contexto terrorista y sin la intención de generar violencia. Algo que no parece ser el espíritu de la ley ni de nuestra jurisprudencia, con habituales referencias a la justificación del castigo cuando sea evidente el "apoyo moral", la "loa a los terroristas", etc... Así parece desprenderse de la jurisprudencia del Tribunal Supremo, para el que las sanciones penales vinculadas a las conductas de incitación o apología del terrorismo podrían justificar una limitación de la libertad de expresión

cuando pueda inferirse que dichas conductas suponen un riesgo para la seguridad nacional, la integridad territorial o la seguridad pública, la defensa del orden o la prevención del delito... bien sea como apoyo moral a la actividad —-mediante el enaltecimiento de la propia actividad ... o como apoyo moral a la ideología a través de la loa a quienes desarrollan esa actividad mediante el enaltecimiento de sus autores ${ }^{37}$.

o "La sanción penal de las conductas de enaltecimiento del terrorismo sancionadas en el artículo 578 supone una legítima injerencia en el ámbito de la libertad de expresión de los autores en la medida en que puedan ser consideradas como una manifestación del discurso del odio por propiciar o alentar, aunque sea de manera indirecta, una situación de riesgo" 38 .

Los tribunales, como vemos, en aras de justificar la limitación de expresiones que no suponen un riesgo real, han introducido en la ecuación un nuevo elemento: el odio.

\footnotetext{
${ }^{36}$ Vid. Nota supra.

37 Tribunal Supremo, STS 221/2017, de 29 de marzo de 2017, Fundamento de Derecho 3.

38 Tribunal Supremo, STS 378/2017, de 25 de mayo de 2017, Fundamento de Derecho 2.
} 


\section{Discurso de odio, libertad de expresión y terrorismo de palabra}

Últimamente es habitual la referencia al odio para condenar todo tipo de conductas y opiniones. Seguramente es producto de la inclusión en el Código penal de los nuevos delitos de odio (art. 510) que tipifican "conductas que fomenten, promuevan o inciten directa o indirectamente al odio por

razón de su pertenencia a aquél, por motivos racistas, antisemitas u otros referentes a la ideología, religión o creencias, situación familiar, la pertenencia de sus miembros a una etnia, raza o nación, su origen nacional, su sexo, orientación o identidad sexual, por razones de género, enfermedad o discapacidad.

Así, que como hemos visto en el apartado anterior, los tribunales también se refieren a él para justificar una limitación en la libertad de expresión por motivos terroristas.

Así, por ejemplo, el propio Tribunal Constitucional, ha entendido que la sanción de acciones que responden al enaltecimiento o a la justificación del terrorismo

supone una legítima injerencia en el ámbito de la libertad de expresión de sus autores en la medida en que pueden ser consideradas como una manifestación del discurso del odio por propiciar, alentar, aunque sea de manera indirecta, una situación de riesgo para las personas o derechos de terceros o para el propio sistema de libertades ${ }^{39}$.

Esta postura es compartida por parte de la doctrina; unos plantean que los delitos tipificados en el artículo 578 CP deben considerarse "como delitos de odio en el ámbito del terrorismo"40, mientras que otros los sitúan "dentro de los delitos de odio con base en el denominado discurso del odio" 41.

Hemos de apuntar, que las conductas que se contemplan en el artículo $578 \mathrm{CP}$ han de tener algún tipo de manifestación que las haga punibles, pues no se puede castigar el odio sin más.

El derecho (...) no puede prohibir el odio, no puede castigar al ciudadano que odia. Por si fuera poco, el vocablo discurso, incluso en su simple acepción gramatical, evoca un acto racional de comunicación cuya punición no debería hacerse depender del sentimiento que anima a quien lo pronuncia $^{42}$.

Por ello, creemos que llegados a este punto es esencial recuperar el argumento del contexto, la intención y el emisor del mensaje. Creemos que podemos considerar estas conductas dentro del "discurso del odio terrorista" cuando provengan de ambientes o contextos marcados por el

\footnotetext{
${ }^{39}$ Tribunal Constitucional, STC 112/2016, de 20 de junio, Fundamento Jurídico 4.

${ }^{40}$ Bernal (2016), p. 19.

${ }^{41}$ Cámara (2017), p. 216.

42 Tribunal Supremo, STS 334/2018, de 4 de julio de 2018, Fundamento de Derecho 3.
} 
terrorismo y la violencia o si las palabras son pronunciadas por sujetos que provienen de ese entorno y cuando la intención (sea quien sea el emisor) sea la de efectivamente ensalzar o justificar a los violentos. Más difícil se nos antoja justificar la limitación de la libertad de expresión cuando nos encontremos con sujetos que no pertenecen a esos grupos ni a otros cercanos a ellos, sino a la sociedad civil y cuya intención es claramente otra. Evidentemente no siempre será fácil discernir en qué contexto nos encontramos ni, por supuesto, cuál es la intención del emisor del mensaje. Pero debemos evitar ampliar sin límite el catálogo del discurso del odio, porque ello supondría una injusta limitación del derecho a opinar y a expresarse en libertad. Y esto por muy odiosas, despreciables y desacertadas que puedan ser las palabras de algunos.

El concepto que se tiene del odio y, por ende, lo que debe ser considerado discurso del odio, depende en cierta medida de la experiencia histórica y de ciertos aspectos sociopolíticos de cada país. En Europa, las leyes contra este tipo de discurso han existido desde finales de la II Guerra Mundial. En 1966 se incluyó en el Pacto Internacional de Derechos Civiles y Políticos de Naciones Unidas y en 2007, la Unión Europea adoptó un acuerdo marco que instaba a los Estados miembros a promulgar leyes que tipificaran como delito aquellos discursos que fomentaran el odio hacia las personas o las humillara.

Actualmente, casi todos los países de Europa cuentan con algún tipo de legislación de este tipo. Bien sea en el Código penal (Alemania, Austria, Bélgica, Bulgaria, Chipre, Croacia, Dinamarca, Eslovaquia, Eslovenia, España, Estonia, Finlandia, Francia, Grecia, Holanda, Hungría, Italia, Letonia, Lituania, Luxemburgo, Malta, Polonia, Portugal, República Checa, Rumanía, y Suecia) o/y en otro tipo de normas (Bélgica, Chipre, Croacia, Escocia, Eslovenia, España, Estonia, Francia, Grecia, Hungría, Irlanda, Irlanda del Norte, Italia, Malta, Reino Unido).

\section{Condenas por terrorismo de palabra a miembros de la sociedad civil}

Nos parece esencial fijar la atención en algunos casos concretos para determinar cómo está siendo aplicada la norma sobre el terrorismo de palabra. Algunos casos han saltado a la prensa e incluso a los medios internacionales, por tratarse de cantantes de rap, humoristas, tuiteros, etc... Esta situación ha generado una corriente de opinión contraria a sus condenas, alentada por la idea de que la libertad de expresión incluye "todo" (algo que como ya hemos apuntado no es 
así) y sostenido por el hecho de que al haberse disuelto la banda terrorista ETA en 2011, la posibilidad de alentar a la violencia es más remota. Podemos decir que en nuestro país existe hoy en día cierta tolerancia social a este tipo de mensaje, pero lo cierto es que, aunque ETA ya no esté operativa, la generación de violencia terrorista es, aún hoy, algo posible en nuestro país.

Alguna de las condenas más mediáticas ha sido la del rapero Valtonyc. En 2017 fue condenado por la Audiencia Nacional ${ }^{43}$ a 3 años y medio de prisión por el delito de enaltecimiento del terrorismo, amenazas e injurias al Rey. La sentencia fue ratificada por el Tribunal Supremo el 15 de febrero de 2018, que consideró probado que las letras de sus canciones constituían "una alabanza, no ya de los objetivos políticos, sino de los medios violentos empleados por las citadas organizaciones terroristas". "Los referidos contenidos no quedan amparados por la libertad de expresión o difusión de opiniones invocada por el acusado y su defensa"44. Algunas de las letras por las que fue condenado: "que tengan miedo, joder, que tengan, miedo"; "Un pistoletazo en la frente de tu jefe está justificado o siempre queda esperar que lo secuestre algún GRAPO"; "Queremos que el miedo llame a sus puertas con llamas"; "o que explote un bus del PP con nitroglicerina cargada", etc.

En 2015 Francisco Sánchez López, un joven sevillano, fue condenado a 1 año y medio de prisión por enaltecimiento del terrorismo a través de una red social, con mensajes como: "Las declaraciones de Jorge Fernández Díaz ${ }^{45}$ son claramente pro ETA. Está pidiendo a gritos un tiro en la nuca" y humillación a las víctimas por supuestos chistes sobre Ortega Lara ${ }^{46}$ e Irene Villa ${ }^{47}$, chistes carentes, según la Audiencia Nacional, de todo contexto humorístico o artístico.

En 2015 Beñat Lasa Fernández, usuario de las redes sociales, fue condenado a 18 meses de prisión por un comentario sobre la muerte de Carrero Blanco ${ }^{48}$, y por publicar entre 2013 y 2014, comentarios que enaltecían a ETA como: "Rajoy ${ }^{49}$ bomba lapa venga po po!!!"; "entre ceja y ceja" (referido a una imagen del general de la Guardia Civil Enrique Rodríguez Galindo); "ETA

\footnotetext{
43 Audiencia Nacional, SAN 494/2017, de 21 de febrero de 2017.

44 Tribunal Supremo, STS 397/2018, de 15 de febrero de 2018.

45 Jorge Fernández Díaz, diputado por el Partido Popular, fue ministro del Interior del Gobierno de España del 22 de diciembre de 2011 al 4 de noviembre de 2016.

${ }^{46}$ José Antonio Ortega Lara, funcionario de prisiones, fue secuestrado por ETA en 1996 y liberado por la Guardia Civil 532 días después.

${ }^{47}$ Irene Villa González sufrió un grave atentado de ETA junto a su madre (funcionaria de la Dirección General de la Policía) cua ndo tenía 12 años. A causa del atentado (el coche en el que viajaba con su madre camino del colegio explotó a causa de una bomba lapa) perdió las dos piernas y tres dedos de la mano izquierda).

${ }^{48}$ Luis Carrero Blanco fue presidente del Gobierno de España del 9 de junio al 20 de diciembre de 1973.

${ }^{49}$ Mariano Rajoy Brey, del Partido Popular, fue presidente del Gobierno de España del 21 de diciembre de 2011 al 2 de junio de 2018.
} 
nunca ha sido vencida y no lo será" y "Yo aplaudiré cuando os vuelen el Patrol. Tenedlo claro. Torturadores asesinos", en referencia a la Guardia Civil.

En 2017 la Audiencia Nacional condenó a 1 año de prisión y 7 de inhabilitación absoluta a Cassandra Vera ${ }^{50}$ por un delito de enaltecimiento del terrorismo en su modalidad de humillación a las víctimas por 13 mensajes de burla en Twitter sobre Carrero Blanco ${ }^{51}$. El Tribunal Supremo la absolvió en $2018^{52}$ al considerar que "no contienen ningún comentario ácido contra la víctima del atentado ni expresan frases o comentarios hirientes, lacerantes o ultrajantes contra su persona o cualquier aspecto concreto de su vida pública o privada", se consideraba que las frases, aunque inapropiadas, respondían a la intención de hacer humor con las circunstancias de aquel atentado en el que hicieron explotar una bomba que hizo volar el coche por encima de una tapia.

Muy mediático fue también el caso de Strawberry, cantante de rap. Fue condenado a un año de prisión y siete años de inhabilitación absoluta para el ejercicio de cargo o empleado público 53 . Fue condenado por publicar tweets como: “Ortega Lara debe ser secuestrado ahora” o "Cuántos deben seguir la fuga de Carrero Blanco". Fue absuelto por el Tribunal Constitucional en $2020^{54}$.

Estos son algunos ejemplos, entre otros muchos, que han hecho surgir el debate sobre si ese tipo de mensajes deben ser considerados o no terrorismo de palabra o si la sociedad debe soportarlos. Obviamente, la duda solo surge si se trata de personas no vinculadas directa ni indirectamente con entornos terroristas y cuya intención no está orientada a generar violencia de ninguna manera, y siempre que sus mensajes se refieran a grupos inactivos. Cuando los mensajes tienen (o pretenden tener) un trasfondo crítico o humorístico, parece que la respuesta debe ser favorable a la libertad de expresión, a pesar de que esas opiniones sean despreciables y carentes de gracia alguna para la mayoría de los miembros de la sociedad. Pero ¿debe darse la misma consideración a aquellos mensajes que ni pretenden hacer una crítica, ni manifestar una opinión ni se encuadran dentro de un contexto artístico o humorístico?

\footnotetext{
${ }^{50}$ Audiencia Nacional, SAN 514/2017, de 29 de marzo de 2017.

${ }^{51}$ Algunas de estas frases fueron: «¿Carrero Blanco también regresó al futuro con su coche? \#RegresoAlFuturo»;

«Feliz 20 de diciembre». (Con la foto del atentado contra Carrero Blanco.); «20D». (Con el montaje de un astronauta con la cara de Carrero Blanco en la superficie lunar.) o «Contigo quiero volar / para poder verte desde el cielo / en busca de lo imposible / que se escapa entre mis dedos». (Con una imagen que recrea la trayectoria ascendente del vehículo de Carrero Blanco.)

52 Tribunal Supremo, STS 95/2018, de 26 de febrero de 2018.

53 Tribunal Supremo, STS 31/2017, de 18 de enero de 2017.

54 Tribunal Constitucional, STC 35/2020, de 25 de febrero de 2020.
} 


\section{Sobre proporcionalidad de las penas y la Teoría del desaliento}

La proporcionalidad es una cuestión que afecta a la norma y a la gravedad de las sanciones establecidas por el legislador para cada caso concreto y que deben ser racionales en función del bien jurídico protegido. El legislador es libre en establecer las penas y su duración, sin que en la Constitución haya ningún artículo que limite su extensión. Sin embargo, el Tribunal Constitucional puede controlar la reacción excesiva de los tipos penales y la aflictividad de las penas. Así lo ha manifestado el Tribunal Supremo cuando dice que

en el juicio sobre la proporcionalidad de las penas compete al legislador en primera instancia...Esa libertad no es absoluta. La Constitución impone unos mínimos estándares de proporcionalidad que enlazan con los derechos proclamados en su artículo 25.1. Esta estimación se ve en la actualidad reforzada por la vigencia del citado artículo 49.3 de la Corte de Derechos de la Unión Europea. Desde este enfoque una ley penal puede ser fiscalizada por el Tribunal Constitucional tanto por resultar patentemente innecesaria una reacción de tipo penal, como por terminar excesivo la carga aflictiva de la pena en relación con la entidad del delito.

El artículo 49.3 recoge: "La intensidad de las penas no deberá ser desproporcionada en relación con la infracción" 55 .

Su exceso puede vulnerar el principio de legalidad contemplado en el artículo 9.3 CE. De otra parte, el juez tiene que valorar en cada caso concreto los hechos y la sanción que corresponde, es decir, tiene que ponderar y tomar en consideración todos los elementos que intervienen en el caso.

El juez ha de decidir si una medida limitativa de un derecho es más o menos gravosa para éste que otras alternativas, $y$, aun no siéndolo, también ha de decidir si exige un sacrificio desproporcionado el derecho en comparación con el beneficio que se reporta para el fin constitucionalmente legítimo que se persigue. Esto es así, porque la desproporción siempre está presente per relationem ${ }^{56}$.

Para asegurar la proporcionalidad de la pena es necesario ponderar elementos como la naturaleza del hecho, la difusión, el ánimo, etc ${ }^{57}$. En todo caso, el Derecho penal no puede jugar como disuasorio de la libertad de expresión.

El Juez penal ha de tener siempre presente su contenido constitucional para no correr el riesgo de hacer del Derecho penal un factor de disuasión del ejercicio de la libertad de expresión, lo que, sin duda, resulta indeseable en el Estado democrático...Así las cosas, el órgano judicial debe valorar, como cuestión previa a la aplicación previa del tipo penal y atendiendo siempre a las circunstancias concurrentes en el caso concreto, si la conducta que enjuicia constituye un ejercicio ilícito del derecho a la libertad de expresión y, en consecuencia, se justifica por el valor

\footnotetext{
55 Tribunal Supremo, STS 716/2014, de 9 de octubre de 2014, Fundamento de Derecho 1.

${ }^{56}$ Álvarez (1999), p. 9.

57 Tribunal Supremo, STS 646/2018, de 14 de diciembre de 2018.
} 
predominante de la libertad de expresión. Pues es obvio que los hechos probados no pueden ser a un mismo tiempo valorados como actos de ejercicio de un derecho fundamental y como conductas constitutivas de delito ${ }^{58}$.

Es importante, pues, tener en cuenta el principio de proporcionalidad ${ }^{59}$ (sobre todo cuando puede estar en juego una limitación exagerada de ciertos derechos fundamental), esto es, que la pena impuesta sea proporcional al daño producido. El principio de proporcionalidad "se compone de tres subprincipios o elementos, que son: el principio de adecuación o idoneidad, el principio de necesidad y el principio de proporcionalidad en sentido estricto"60. El principio de idoneidad se refiere a que la medida tomada sea útil para el fin que se persigue. El de necesidad implica que no existe otra medida menos restrictiva para el derecho limitado, con la que podría conseguirse los mismos resultados. El de proporcionalidad en sentido estricto exige que el sacrificio merezca la pena dado el beneficio que se obtiene.

El TEDH se ha pronunciado en múltiples ocasiones sobre la proporcionalidad de las sanciones en supuestos de discurso de odio. En concreto, en el caso Otegi vs. España, el Tribunal destacaba que "la naturaleza y la dureza de las penas impuestas son también elementos que deben tenerse en cuenta cundo se trata de medir la proporcionalidad de la injerencia" 61 . En este caso, se consideró que la pena era desproporcionada (prisión e inhabilitación para desempeñar cargo público). En la Recomendación de Política General № 15 de la Comisión contra el Racismo y la Intolerancia (apartado 172) también se hace referencia a la proporcionalidad, al considerar que “cualquier sanción que se imponga en un determinado caso ha de reflejar el principio de proporcionalidad ya que cualquier error en este sentido puede ser motivo de vulneración del principio de libertad de expresión".

En relación con el terrorismo de palabra es esencial evitar que se produzca una expansión punitiva que pueda afectar a otros derechos 62 , entre ellos conculcar el derecho a la libertad de expresión63. Así pues, para asegurar la proporcionalidad de las penas, habrá que valorar cada caso concreto, si bien podemos decir que, a priori, no parecen ser excesivas ${ }^{64}$ si se comparan con

\footnotetext{
58 Tribunal Supremo, STS 117/2015, de Fundamento de Derecho 2b).

${ }^{59}$ Cuerda (2017).

${ }^{60}$ Magdaleno (2007), p. 192.

${ }^{61}$ Tribunal Europeo de Derechos Humanos, STEDH de 15 de marzo de 2011.

62 Bernal (2016), p. 17.

${ }^{63}$ Alonso (2010), p. 77.

${ }^{64}$ La pena que se establece es la de prisión de uno a tres años, si bien la tendencia de los Tribunales es a imponer la pena en su límite más bajo: un año de prisión, en menos casos un año y seis meses, y son excepcionales las penas de dos años de prisión. Si tenemos en cuenta que en España la entrada en prisión no se hace efectiva en penas inferiores a tres años, inferimos que cuan do la pena por este tipo de delito implica la entrada efectiva en prisión, es porque no es el único delito cometido por el sujeto o porque este es reincidente. El juez también podrá acordar en la sentencia, durante el período de tiempo que él mismo señale, penas de inhabilitación.
} 
las establecidas para otros delitos ${ }^{65}$. Se considerarán agravantes que los hechos lleven a cabo con publicidad, esto es, que se difundan a través de los medios de comunicación, internet, o cualquiera otra tecnología de la información. También cuando los hechos alteren gravemente la paz pública o creen un grave sentimiento de inseguridad o temor en toda la sociedad o en parte de ella. Como medida cautelar o definitiva el juez podrá ordenar la destrucción de todos los materiales empleados (documentos, grabaciones, etc.) y, si se hubiera perpetrado a través de medios digitales, podrá solicitar el borrado de los contenidos ilícitos tanto de sus sitios web como de los buscadores.

Hay que advertir, además, que en el supuesto de que el juez o tribunal no tenga claro si la libertad de expresión ampara al sujeto frente al delito, es decir, duda de si la conducta es o no punible, debe prevalecer la libertad de expresión, es decir, el comportamiento será impune, no porque la libertad de expresión sea un derecho fundamental sino por el principio in dubio pro reo, es decir, que en caso de duda el juez o tribunal debe absolver.

Sobre la cuestión de "casos de duda" es doctrina consolidada del Tribunal Constitucional en relación a la exaltación/justificación del terrorismo, que

Reconociendo la tensión que existe entre este delito y el derecho a la libertad de expresión de ideas y libertad ideológica, la labor judicial, como actividad individualiza que es, en un riguroso análisis, caso por caso, habrá que examinar tanto las concretas frases o expresiones producidas así como la ocasión y el escenario en el que fueron pronunciadas y, en fin, todas las circunstancias concurrentes, para determinar si está dentro del ámbito del tipo penal o extramuros de él, sin olvidar que el principio favor libertatis necesariamente en los casos de duda, ante la naturaleza constitucional de los derechos de la libertad de expresión e ideológica que podrían quedar afectados por el tipo penal, derechos que constituyen una de las más acusadas señas de identidad de la Sociedad Democrática66.

Es decir, ante la duda hay que respetar el principio in dubio favor libertatis: en caso de duda a favor de la libertad.

La proporcionalidad en las sanciones es muy relevante, pues la imposición de sanciones desproporcionadas (en relación con el discurso del odio y el cercano al terrorismo de palabra) puede producir un efecto de desaliento. Esto es, puede provocar un efecto disuasorio en el ejercicio de la libertad de expresión o información. El desaliento se produce respecto a conductas lícitas que suelen estar en el límite de las ilícitas ${ }^{67}$. El ciudadano no se siente seguro en el ejercicio de tales derechos, porque, por un lado, no sabe exactamente hasta dónde puede llegar el ejercicio

${ }^{65}$ Magdaleno (2007).

66 Tribunal Constitucional, STC 112/2016, de 20 de junio de 2016.

${ }^{67}$ Cuerda (2014), p.174. 
de su derecho y, por otro, porque teme ser castigado con penas altas, lo que influye negativamente en su toma de decisiones. Este efecto disuasorio, no obstante, puede producirse tanto por la desproporción de la pena o sanción contemplada en un texto legal como por la incorrecta aplicación de los jueces en casos concretos. En suma, la situación puede llevar a provocar una autocensura en el ejercicio de la libertad de expresión e información haciendo uso de estas en un límite inferior al que legalmente le estaba permitido.

Otro factor que puede favorecer el desaliento es la condena a miembros de la sociedad civil por delitos graves y despreciables (como son los delitos de terrorismo), cuando su conducta está relacionada con la palabra. Es el caso de las condenas por terrorismo a cantantes, blogueros, etc., o la denuncia (y detención en muchos casos) de personas anónimas por mensajes (en las redes sociales) extremos contra personas públicas.

\section{Conclusiones}

Desde nuestro punto de vista, la libertad de expresión debe considerarse un derecho preferente, aunque no ilimitado. Creemos que la libertad de expresión ampara también opiniones extremas incluso cuando puedan resultar despreciables para la sociedad, sean en el sentido que sean. Pero también creemos que hay ciertas conductas que no están amparadas por ella, aquellas cuyo objetivo es la generación de violencia. Que estén orientas a ello y que, además, puedan realmente provocarla. No bastaría, pues, con la intención, sino que además bebe existir una posibilidad real. Así, es evidente que la apología del terrorismo debe ser condenada como terrorismo de palabra toda vez que el objetivo de dicha conducta es precisamente la provocación a otros para generar más violencia terrorista. En cuanto al delito de humillación a las víctimas, debería considerarse subsumido por el delito de injurias (no dentro en los delitos de terrorismo de palabra). Debería incluirse entre las injurias que son delitos perseguibles a instancia de parte, es decir, que solo se investigan si la parte ofendida lo reclama. Así, evitaríamos que lo que hasta hace poco eran simples bromas o chistes (aunque poco afortunados o incluso desagradables) sean hoy en día perseguidos como delitos de terrorismo.

En cuanto a los delitos de enaltecimiento y justificación, la respuesta no es tan simple. Creemos que debe considerarse protegida por la libertad de expresión cualquier opinión, idea o manifestación que no esté orientada a generar violencia, pero no las que sean susceptibles de 
generarla de manera real ${ }^{68}$. Esto implica analizar el tipo de persona que emite el mensaje (no es lo mismo ser un político, un líder religioso, o un activista que un simple ciudadano por muchos o pocos seguidores que se tengan en las redes sociales), el contexto (no es lo mismo que el grupo terrorista siga activo que no), el receptor (no es lo mismo que el público sea un grupo de afines a estos mensajes pro terroristas que ciudadanos ajenos o incluso contrarios a estos mensajes), y la intencionalidad (no se tratará igual al que busca convencer, reclutar o alentar la violencia que al que da una opinión) ${ }^{69}$.

Así pues, creemos que los delitos de enaltecimiento y justificación del terrorismo no deben ser despenalizados ${ }^{70}$, si bien deben estar definidos y delimitados de tan forma que no interfieran en la libertad de expresión más allá de lo estrictamente necesario, para lo que deberán tomarse en consideración no solo el mensaje, sino, además, todos y cada uno de los criterios apuntados más arriba: emisor, receptor, contexto e intencionalidad. Caso contrario nos encontraríamos sin instrumentos jurídicos para castigar y luchar contra la exaltación de los actos violentos de grupos activos y que, sin llegar a hacer apología, pudieran influir en ciertos sujetos y provocar acciones violentas a medio o largo plazo. Esto implica hacer un exhaustivo estudio de cada caso, pues para que esas manifestaciones puedan estar amparadas por la libertad de expresión, es preciso que conlleven un trasfondo de crítica y/o de relevancia pública y/o se encuadren en un contexto artístico o humorístico.

El objetivo no es favorecer la glorificación del terrorismo y de los que con la violencia causan el terror, sino de evitar que se condene por terrorismo (de palabra) a miembros de la sociedad civil ajenos a la acción violenta, por muy despreciables que sean sus opiniones, limitando de manera injusta y desproporcionada su libertad de expresión.

\footnotetext{
${ }^{68}$ Galán (2018), p. 293.

${ }^{69}$ Mira (2018), p. 318.

70 El 6 de marzo de 2020 se publicó en el Boletín Oficial de las Cortes Generales una Proposición de ley presentada por el Grupo Parlamentario Unidas Podemos (partido comunista) para que se derogue el artículo $578 \mathrm{CP}$, relativo al enaltecimiento del terrorismo. Por su parte, el Grupo parlamentario Popular (partido conservador) ha presentado otra (publicada en el Boletín Of icial de las Cortes Generales el 14 de mayo de 2020 para que se agraven las penas del art. 578 CP "cuando los hechos fueran cometidos por autoridad, funcionario público o representante de un partido político...". Aunque se suprimiera el artículo las conductas que ahora se contemplan en el mismo se podrían perseguir por el artículo 579 del Código "cuando fueran idóneas para incitar a otros a la comisión de un delito de terrorismo. En septiembre de 2018 el Grupo Parlamentario Unidas Podemos presentó una proposición no de ley en el Parlamento para despenalizar, entre otros, el enaltecimiento del terrorismo.
} 


\section{Bibliografía citada}

Alonso Rimo, Alberto (2010): “Apología, enaltecimiento del terrorismo y principios penales", en Revista de Derecho Penal y Criminología, (3ª época, № 4), pp. 13-80.

Álvarez Conde, Enrique y González Rodríguez, Hortensia (2006): “Legislación antiterrorista comparada después de los atentados del 11 de septiembre y su incidencia en el ejercicio de los derechos fundamentales", en Revista Real Instituto El Cano de Estudios Internacionales y Estratégicos, (ARI № 7). [Fecha de consulta: 8 de abril de 2020] [Disponible en: https://bit.ly/3fNdpd3].

Aláez Corral, Benito, (1999): “El principio de proporcionalidad del legislador penal y la defensa de la Constitución”, en Repertorio Aranzadi del Tribunal Constitucional, (№ 15) pp. 4-19.

Arias Castaño, Abel (2007): “Amenazas. Enaltecimiento del terrorismo y libertad de expresión: El caso De Juana Chaos", en Revista InDret, (octubre), pp. 2-28.

Bernal del Castillo, Jesús (2016): “El enaltecimiento del terrorismo y la humillación a sus víctimas como formas del discurso del odio", en Revista de Derecho penal y Criminología, (3 ${ }^{a}$ época, № 16), pp. 13-43

Bernal Pulido, Carlos (2007): El principio de proporcionalidad y los derechos fundamentales (Madrid, Editorial Centro de estudios Políticos y Constitucionales).

Cámara Arroyo, Sergio (2017): "El concepto del delito de odio su comisión a través del discurso del odio. Especial referencia al conflicto con la libertad de expresión", en Anuario de Derecho Penal y Ciencias Penales, (vol. LXX), pp. 139-225.

Carrasco Andino, Ma del Mar (2019): “Derechos fundamentales y legislación antiterrorista. ¿Qué hemos perdido por el camino?”, en Estudios Penales y Criminológicos, (vol. XXXIX), pp. 59-105.

Cuerda Arnau, Ma Luisa (2007): “Proporcionalidad penal y libertad de expresión: la función dogmática del efecto desaliento", Revista General de Derecho Penal, núm. 8, pp. 1-43.

Cuerda Arnau, Ma Luisa (2014): “Proporcionalidad penal. Libertad de expresión y efecto de desaliento. Su proyección sobre los nuevos tipos de apología”, Lascuraín Sánchez, Juan 
Antonio y Rusconi, Maximiliano Adolfo: El principio de proporcionalidad penal, (Buenos Aires, Editorial AD-HOC SRL), pp. 151-201

Dolz Lago, Manuel Jesús (2013): “Delito de descrédito, menosprecio o humillación víctimas del terrorismo: diferencias con el delito de enaltecimiento o justificación en los delitos de terrorismo", en Diario La Ley, (№ 8152).

Fernández Martínez, Juan Manuel (2010): “Enaltecimiento del terrorismo”, en Revista Aranzadi Doctrinal, (№ 10), pp. 37-44.

Galán Muñoz, Alfonso (2018): “El delito de enaltecimiento terrorista. ¿Instrumento de lucha contra el peligroso discurso del odio terrorista o mecanismo represor de repudiables mensajes de raperos, twitteros y titiriteros?", en Estudios Penales y Criminológicos, (vol. XXXVIII), pp. 245-304.

Galvez Montes, Javier (2001): “Artículo 20”, en Garrido Falla, Fernando (2001): Comentarios a la Constitución, (Madrid, Editorial Civitas), pp. 400-440.

Gay Fuentes, Celeste (1989): “La jurisprudencia del Tribunal Europeo de Derechos del Hombre en materia de libertad de expresión y su aplicación por el Tribunal Constitucional español", en Revista de Administración Pública, (№ 120), pp. 259-276.

García Roca, Javier (2010): El margen de apreciación nacional en la interpretación del Convenio Europeo de Derechos Humanos: Soberanía e integración, (Madrid, Editorial Aranzadi).

Korff, Dowe (1998): "The guarantee of freedom of expression under article 10 of the European Convencion on Human Rights", en Media Law and Practice, (diciembre 1998, vol. 9, № 4), pp. $143-150$.

Magdaleno Alegría, Antonio (2007): “Libertad de expresión, terrorismo y límites de los derechos fundamentales", en Revista de Derecho Público, (№ 69), pp. 181-218.

Magdaleno Alegría, Antonio (2007): “Libertad de expresión y partidos políticos en la jurisprudencia del Tribunal Europeo de Derechos Humanos”, en AFDUDC, (№ 11), 2007 
Meza-Lopehandía, Matías y Wiliams Obreque, Guido (2018): "Evolución de la legislación antiterrorista: Chile y España", [Fecha de consulta: 15 de mayo de 2020]. [Disponible en: https://bit.ly/3wTYjIs].

Mir Puig, Santiago y Corcoy Bidasolo, Mirentxu (dirs.) (2012): Protección penal de la libertad de expresión e información (Valencia, Editorial Tirant lo Blanch).

Mira Benavent, Javier (2018): "El delito de enaltecimiento del terrorismo, el de humillación a las víctimas del terrorismo y la competencia de la Audiencia Nacional: ni delito, ni terrorismo, ni competencia de la Audiencia Nacional”, en Alonso Rimo, A. (Dir.) Terrorismo, sistema penal y derechos fundamentales, (Valencia, Editorial Tirant lo Blanch).

Moreno Bobadilla, Ángela (2017): "La influencia europea en el ámbito de los derechos fundamentales en España, en concreto, en el derecho a la intimidad", en Estudios Constitucionales, (Año 15, № 2), pp. 301-330.

Ruiz Landáburu, Maㅡ José. (2002): Provocación y apología: delitos de terrorismo. (Madrid, Editorial Colex)

Sánchez de Diego Fernández de la Riva, Manuel (2010): “Una nueva libertad de expresión para una nueva sociedad", en Diálogos de la Comunicación, (№ 82 septiembre-diciembre de 2010) [Disponible en: https://bit.ly/3zHvEbE] [Fecha de Consulta: 25 de julio de 2020]

Santiago Ramírez, Vanessa y Valentín Cotobal, Víctor (2019): Enaltecimiento del terrorismo. Análisis jurisprudencial y policial del artículo 578 del Código penal, (A Coruña, Editorial Colex).

Serrano maillo, Ma Isabel (2020): “Anti-terrorism regulations in Spain and freedom of expresión", Workneh, Téwodros y Haridakis, Paul (edits.): Counter Terrorism Laws and Freedom of Expression: Global Perspectives (Lonres, Routledge).

Suárez Espino, Ma Lidia (2007): “Los derechos de comunicación social en la jurisprudencia del Tribunal Europeo de Derechos Humanos y su influencia en el Tribunal Constitucional español", en la Revista de Derecho Constitucional Europeo de la Universidad de Granada, № 7) [Disponible en: https://bit.ly/3iamkqs] [Fecha de Consulta: 25 de julio de 2020]. 
Tapia Rojo, Mạ Eugenia (2016): “Análisis de la estrategia comunicativa del terrorismo yihadista. El papel de las redes sociales", en Revista del Instituto Español de Estudios Estratégicos, (enero-marzo № 1), pp. 370-384.

\section{Normas jurídicas citadas}

Ley Orgánica 1/1982, de 5 de mayo de 1982, de Protección Civil del Derecho al Honor, a la Intimidad personal y familiar y a la propia imagen.

Ley Orgánica 10/1995, de 23 de noviembre de 1995, del Código Penal.

Ley Orgánica 7/2000, de 22 de diciembre de 2000, de modificación de la Ley Orgánica 10/1995, de 23 de noviembre, del Código Penal, y de la Ley Orgánica 5/2000, de 12 de enero, reguladora de la Responsabilidad Penal de los Menores, en relación con los delitos de terrorismo.

Ley Orgánica 6/2002, de 27 de junio de 2002, de Partidos Políticos.

Ley Orgánica 2/2015, de 30 de marzo de 2015, por la que se modifica la Ley Orgánica 10/1995, de 23 de noviembre, del Código Penal, en materia de delitos de terrorismo.

Directiva (UE) 2017/541) del Parlamento Europeo y del Consejo, de 15 de marzo de 2017.

\section{Jurisprudencia citada}

Tribunal Europeo de Derechos Humanos: Handyside c. Reino Unido, Demanda № 5493/72, de 7 de diciembre de 1976, [Disponible en: https://bit.ly/3iqNDx1].

Tribunal Europeo de Derechos Humanos: De Haes y Gijsels c. Bélgica, Demanda № 00019983/92, de 24 de febrero de 1997, [Disponible en: https://bit.ly/3z233h4].

Tribunal Europeo de Derechos Humanos: Linges c. Austria, Demanda № 9815/82, de 8 de julio de 1986, [Disponible en: https://bit.ly/3fJ7J3y].

Tribunal Constitucional de España: El País, STC 171/1990, de 12 de noviembre de 1990. 
Tribunal Europeo de Derechos Humanos: Jerusalem c. Austria, Demanda №. 26958/95, de 27 de febrero de 2001, [Disponible en: https://bit.ly/2STW5tS].

Tribunal Europeo de Derechos Humanos: Colombani c. Francia, Demanda №. 51279/99, de 25 de junio de 2002, [Disponible en: https://bit.ly/3ce6Rlz].

Tribunal Supremo: Herritarrok y Batasuna, STS 2133/2003, de 27 de marzo de 2003 (sentencia sobre la ilegalización de los partidos políticos Herry Batasuna, Euskal Herritarrok y Batasuna) [Disponible en: https://bit.ly/3qhqvmv].

Tribunal Constitucional de España: Batasuna, STC 5/2004, de 16 de enero de 2004 (Resolución del recurso de amparo interpuesto por Batasuna contra su ilegalización) [Disponible en: https://bit.ly/3uLkJdl].

Tribunal Constitucional de España: Herritarren Zerrenda, STC 99/2004, de 27 de mayo de 2004 (Recurso de amparo interpuesto por Herritarren Zerrenda contra la decisión de excluir su candidatura a las elecciones). [Disponible en: https://bit.ly/3if517t].

Audiencia Nacional: Pablo Rivadulla Duró (Hásel), SAN 8/2014, de 31 de marzo de 2014 (Sentencia condenatoria por enaltecimiento del terrorismo), [Disponible en: https://bit.ly/2S5wi1I].

Tribunal Supremo: Pablo Rivadulla Duró (Hásel), STS 748/2015, de 19 de febrero de 2015 (Recurso de casación contra la sentencia condenatoria por enaltecimiento del terrorismo). [Disponible en: https://bit.ly/3d0GaAY].

Tribunal Constitucional de España: Jaume Roura Capellera y Don Enric Stern Taulats, STC 177/2015, de 22 de julio de 2015, (Recurso de amparo contra la sentencia que los condena por un delito de injurias a la Corona), [Disponible en: https://bit.ly/3ibQVUD].

Tribunal Constitucional de España: Tasio Erkizia Almandoz , STC 112/2016, de 20 de junio de 2016. (Recurso de Amparo contra la sentencia que lo condena por un delito de exaltación del terrorismo y discurso de odio por el elogio público de un terrorista) [Disponible en: https://bit.ly/3uURMMh]. 
Tribunal Supremo: César Augusto Montaña Lehma (Strawberry), STS 31/2017, de 18 de enero de 2017 (Recurso de casación en que se condena por enaltecimiento del terrorismo y humillación a las víctimas), [Disponible en: https://bit.ly/3iaOUrB].

Audiencia Nacional: Josep Miquel Arenas Beltrán (Valtonyc), SAN 494/2017, de 21 de febrero de 2017. (Sentencia condenatoria por enaltecimiento del terrorismo), [Disponible en: https://bit.ly/3vLIGTf]

Audiencia Nacional: Ramón Vera (Cassandra), SAN 514/2017, de 29 de marzo de 2017 (sentencia condenatoria por humillación a las víctimas del terrorismo), [Disponible en: https://bit.ly/2SVCB7V].

Pedro Miguel (sentencia anonimizada) (2017): Tribunal Supremo, STS 221/2017, de 29 de marzo de 2017 (Recurso de casación contra sentencia condenatoria por enaltecimiento del terrorismo), [Disponible en: https://bit.ly/2SJsL9L].

Tribunal Supremo: Jesús Luis (sentencia anonimizada), STS 378/2017, de 25 de mayo de 2017 de 2017 (Recurso de casación contra sentencia condenatoria por enaltecimiento del terrorismo) [Disponible en: https://bit.ly/3gHrYzc].

Audiencia Nacional: Fernando de Reyna, SAN 25/2017, de 11 de diciembre de 2017(sentencia condenatoria por enaltecimiento del terrorismo), [Disponible en: https://bit.ly/3wSE39T].

Tribunal Supremo: Josep Miquel Arenas Beltrán (Valtonyc), STS 397/2018, de 15 de febrero de 2018. (Recurso de casación contra la sentencia que lo condenaba por enaltecimiento del terrorismo), [Disponible en: https://bit.ly/3gNgpX2].

Tribunal Supremo: Ramón Vera (Cassandra), STS 95/2018, de 26 de febrero de 2018 (Recurso de casación contra sentencia que la condenaba por delito de humillación a las víctimas), [Disponible en: https://bit.ly/3xzhxm0].

Tribunal Supremo: Mauricio (sentencia anonimizada), STS 334/2018, de 4 de julio de 2018, [Disponible en: https://bit.ly/2TRbEmD].

Tribunal Constitucional de España: César Augusto Montaña Lehma (Strawberry), STC 35/2020, de 25 de febrero de 2020, (Recurso de amparo en el que se absuelve del delito de 
enaltecimiento del terrorismo y humillación a las victimas), [Disponible en: https://bit.ly/3yZDRYb]. 